\title{
Technical efficiency in the sheep dairy industry: an application on the Sardinian (Italy) sector
}

\author{
Roberto Furesi, Fabio A Madau* and Pietro Pulina
}

\author{
* Correspondence: famadau@uniss.it \\ Department of Science for Nature \\ and Environmental Resources, \\ University of Sassari, Via Enrico de \\ Nicola 1, Sassari 07100, Italy
}

\begin{abstract}
Sardinia (Italy) is one of the most important European regions for sheep dairy and sheep milk cheese production. However the Sardinian sheep dairy industry is currently going through a dramatic crisis, and verifying whether it can recover part of its profitability is now a priority. Attention is now focused on estimating whether the sheep dairy firms can improve their productivity by more efficient use of their available technical resources. This paper aims to estimate technical efficiency in the Sardinian sheep dairy industry. A stochastic frontier analysis approach was used on panel data from 36 sheep dairy firms over the period 2004-2009 in order to assess whether there are some margins for technical improvements in productivity, given the existing level of technology. A comparative analysis of private firms and cooperatives was also carried out, in order to establish if there were differences in the technology they used and/or their efficiency in using technical inputs. Our findings suggest that there is technological homogeneity among the firms and between private firms and cooperatives. Technical efficiency is equal to 0.905 and it is significantly different between private firms (0.933) and cooperatives (0.877). Our findings have certain implications for what policies should be implemented in order to improve efficiency in the sector and on the orientation of decision makers strategies.
\end{abstract}

Keywords: Sheep dairy industry, Technical efficiency, Stochastic Frontier Analysis (SFA), Private firms and cooperatives, Sardinia

\section{Background}

Sardinia (Italy) is one of the most important EU regions for sheep dairy production. It has more than 3.5 million sheep (3.7\% of the EU total in 2009) ${ }^{\text {a] }}$ that totally produce more than $300,000 \mathrm{MT}$ of milk. This quantity corresponds to about $4 \%$ of total world production (Istat, 2011; FAO, 2011; Eurostat 2011) and the sheep milk is processed into different types of cheese. Sardinia produces approximately 50-60 thousand MT of cheese a year, manufactured by more than 50 dairy factories, about half of which are cooperatives.

More than half of the cheese produced is Pecorino Romano (PR), one of the most important sheep cheeses in the world. An average of 29,100 MT of PR a year was produced between 2000 and 2009 (Consorzio per la tutela del formaggio Pecorino Romano, 2011). Approximately 70\% of PR production is exported (18,500 MT on average a year between 2000 and 2009), with $80 \%$ to $85 \%$ of the export going to the USA. As Sardinia is the largest supplier of PR to the USA, Sardinian PR represents about 70\%

(c) 2013 Furesi et al.; licensee Springer. This is an Open Access article distributed under the terms of the Creative Commons Attribution License (http://creativecommons.org/licenses/by/2.0), which permits unrestricted use, distribution, and reproduction in any medium, provided the original work is properly cited. 
of the volume of the US sheep cheese market (FAS-USDA, 2011). Some processing firms are also exporters. They export their own cheese and what they buy from other dairies.

The US PR market is currently experiencing its worst crisis in years. This is due to a decline in domestic demand and fierce price competition from US cow milk cheese (Idda et al., 2010a). US imports of sheep milk cheese decreased dramatically between 2005 and 2009, from 26,000 MT to less than 20,000 MT (a fall of 24.3\%). Imports from Sardinia fell from 18,200 MT to 13,100 MT (a fall of 28.3\%). The average cheese prices peaked at $\$ 10.70$ a kilo in November 2008, started deceasing in 2009 , and fell to $\$ 6.62$ a kilo in June 2010, a drop of $26.9 \%$ when compared to the average price in 2008.

Effects of the crisis in the US market were immediately felt in Sardinia. The dairy industry paid Sardinian breeders 20\% less for their milk in 2010 than they did in 2008. Sardinian sheep farms operate with low profit margins (Idda et al., 2010b). As a result, if prices were to fall for a prolonged period, many of them would have to go out of business. This would have a serious impact on productivity and the Sardinian economy in general, as well as on externalities and public goods produced by sheep farming in each farm, such as protecting the environment and the landscape, and preserving the vitality of rural communities and the lifestyle of their inhabitants.

Hence, it is of value to see whether the profitability of the Sardinian milk cheese industry can be improved. Given the central role played by the cheese producers - both private firms and cooperatives produce and export cheese - it may be useful to focus on them.

This paper aims to evaluate technical efficiency in the Sardinian sheep dairy processing sector. A stochastic frontier analysis approach was used on a panel data from 36 sheep dairy processors over the period 2004-2009, in order to assess whether there are some margins for technical improvements in productivity, given the present state of technology. In other words, our analysis was focused on estimating whether sheep dairy processors could improve their productivity by using their available resources more efficiently, without considering the prices of outputs and inputs. Particular attention was paid to determine the input-output elasticities, the role of inefficiency in explaining different levels of productivity in different firms, and the effects of a number of particular variables on inefficiency. A comparative analysis of private firms and cooperatives was also carried out, in order to establish if there were differences in the technology they used and/or their efficiency in using inputs.

\section{Methods}

Technical efficiency and the Stochastic Frontier Analysis (SFA)

According to Farrell's well-known model (Farrell 1957), technical efficiency is defined as the measure of the ability of a firm to obtain the best production from a given set of inputs (output-increasing oriented), or as a measure of the ability to use the minimum feasible amount of inputs, given a determined level of output (input-saving oriented) (Greene, 1980; Atkinson and Cornwell, 1994) ${ }^{[\mathrm{b}]}$.

This sub-section briefly illustrates how technical efficiency output-oriented measures can be obtained from Stochastic Frontier Analysis (SFA) models. SFA was originally 
and independently proposed by Aigner et al. (1977) and Meeusen and van der Broeck (1977). A stochastic frontier production function for panel data can be written as:

$$
\begin{aligned}
& y_{i t}=f\left(x_{i t}, t ; \beta\right) \cdot \exp (e) \\
& e=\left(v_{i t}-u_{i t}\right) i=1,2, \ldots N t=1,2, \ldots T
\end{aligned}
$$

where $y_{i t}$ denotes the level of output for the $i$-th observation at year $t ; x_{i t}$ is the row vector of inputs; $t$ is the time index, $\beta$ is the vector of parameters to be estimated; $f(\bullet)$ is a suitable functional form for the frontier (generally Translog or Cobb-Douglas); $v_{i t}$ is a symmetric random error assumed to account for measurement error and other factors not under the control of the firm; and $u_{i t}$ is an asymmetric non-negative error term assumed to account for technical inefficiency (Kumbhakar and Lovell, 2000).

The $v_{i}^{\prime}$ 's are usually assumed to be independent and identically distributed $N\left(0, \sigma_{v}^{2}\right)$ random errors, independent of the $u_{i t}$ 's, which are assumed to be independent and identically distributed and with truncation (at zero) of the normal distribution $\left|N\left(0, \sigma_{u}^{2}\right)\right|$. The Maximum Likelihood Estimation (MLE) of (1) allows us to estimate the vector $\beta$ and the variance parameters $\sigma^{2}=\sigma_{u}^{2}+\sigma_{v}^{2}$ and $\gamma=\sigma_{u}^{2} / \sigma_{u}^{2}+\sigma_{v}^{2}$; where $0 \leq \gamma \leq 1$ (Coelli, 1996) ${ }^{[\mathrm{c}]}$. The technical efficiency $\left(\mathrm{TE}_{i}\right)$ measure is obtained from the ratio of $y_{i t}$ to the maximum achievable level of output $\left(y^{*}\right)$ that lies on the frontier $\left(u_{i t}=0\right)$ and it is given by:

$$
T E=\frac{y i t}{y *}=\frac{f(x i t, t, \beta) \cdot \exp (\varepsilon)}{f(x i t, t, \beta) \cdot \exp (v i)}=\exp \left(-u_{i}\right)
$$

It means that technical efficiency depends only on the inefficiency component under the control of the firm $\left(u_{i t}\right)$. Assuming a semi-normal distribution for $u_{i t}$ and according to Jondrow et al. (1982), we are able to estimate the degree of technical efficiency of each firm.

Some authors have proposed SFA models in which the inefficiency effects $\left(\mathrm{u}_{\mathrm{i}}\right)$ are expressed as a function of a vector of observable explanatory variables and all parameters - frontier production and inefficiency effects - are estimated simultaneously (Kumbhakar et al., 1991; Reisfschneider and Stevenson, 1991; Huang and Liu, 1994). These approaches were adapted by Battese and Coelli (1995) to take into account panel data. They proposed a model where the functional relationship between inefficiency effects and the firm-specific factors was directly incorporated into the MLE. The inefficiency term $u_{i t}$ has a truncated (at zero) normal distribution with mean $m_{i t}$ :

$$
u_{i t}=m_{i t}+W_{i t}
$$

where $W_{i t}$ is a random error term which is assumed to be independently distributed, with a truncated (at $-m_{i t}$ ) normal distribution with mean zero and variance $\sigma^{2}$ (i.e. $W_{i t} \geq-z_{i t}$ such that $u_{i t}$ is non-negative). The mean $m_{i t}$ is defined as:

$$
m_{i t}=Z\left(z_{i t}, d\right) \quad i=1,2, \ldots N \quad t=1,2, \ldots T
$$

where $\mathrm{Z}$ is the vector $(\mathrm{Mx} 1)$ of the $z_{i t}$ firm-specific inefficiency variables of inefficiency; and $\delta$ is the $(1 \mathrm{xM})$ vector of unknown coefficients associated with $z_{i t}$. This allows us to estimate the inefficiency effects arising from the $z_{i t}$ explanatory variables. 


\section{Data and empirical model}

Data were collected on a balanced panel data from 36 sheep dairy processors in Sardinia. The sample consisted of 18 private firms and 18 cooperatives ${ }^{[\mathrm{d}]}$.

The panel data covered a six-year period from 2004 to 2009 for a total of 216 observations. Information came from the Official Register of Accounts, specifically from the income statement, that firms have to submit to the "Register of the Companies" of the Italian Chambers of Commerce, Industry, Handicrafts and Agriculture (C.C.I.A.A.) [e] In other words, we used economic and financial data reported in the available official balance sheets to describe the sheep dairy production process in Sardinia. We assumed a Translog functional form as the frontier technology specification for the sheep dairy firms. This model is similar to the Battese and Coelli (1995) model, with a non-neutral specification for the production frontier function. Basically, following Huang and Liu (1994), the model assumes that technical efficiency depends on both the method of application of inputs and the intensity of input use (Karagiannis and Tzouvelekas, 2005).

Thus the inefficiency term $u_{i t}$ explained by (3) is equal to:

$$
u_{i t}=d_{0}+d_{i t} z_{i}+d_{m} \ln x_{m i t}+W_{i t} \quad i=1,2, \ldots N \quad t=1,2, \ldots T
$$

which allows us to evaluate the role of inputs in conditioning inefficiency.

The Translog stochastic function production model is specified as follows:

$$
\ln Y_{i t}=\beta_{0}+\sum_{j=1}^{5} \beta_{j} \ln x_{j i t}+\frac{1}{2} \sum_{j \leq}^{4} \sum_{k=1}^{4} \beta_{j k} \ln x_{j i t} \cdot \ln x_{k i t}+(v i t-u i t)
$$

where four explanatory variables are used to describe the production frontier (a fifth dummy variable is added in order to identify possible technological differences between private firms and cooperatives).

The dairy output was aggregated into one category $(Y)$, which represents the value of sheep cheeses (and by-products) produced by each firm in a certain year (measured in Euros).

The aggregate inputs that were included as variables of the production function are as follows:

- $\mathrm{X}_{1}$ Intermediate inputs used in the production process: the cost of intermediate inputs spent by firms (measured in Euros);

- $\mathrm{X}_{2}$ Labour used in each firm in terms of total wages paid to workers (measured in Euros);

- $\mathrm{X}_{3}$ Capital: measured in terms of annual depreciation rate so as to have a measure of the average annual use of the capital stock (measured in Euros);

- $\mathrm{X}_{t}$ Time : the year of observation, so that the technological progress component can be captured $(2004=1 ; 2005=2 ; \ldots . .2009=6)$.

As mentioned above, a further variable was inserted in the model, a dummy variable $X_{p}$ that describes the organisational form of the firms, i.e. private firms $\left(X_{p}=1\right)$ or cooperatives $\left(X_{p}=0\right)$. This variable was inserted in order to evaluate if there were technological differences between the two types of firm and so to analyse whether they are part of a single or two different production frontiers. 
Taking into account formula (4), the inefficiency model (5a) has the following form:

$$
u_{i t}=\delta_{0}+\delta_{1} Z_{1 i t}++W_{i t}
$$

Explanatory firm-specific variables of the inefficiency effects were represented by $\mathrm{Z}_{1}$. This reflects the Age of the firms and - according to the non-neutral model proposed by Huang and Liu (1994) - the same pool of variables (included time) used to describe the production frontier function $\left(\mathrm{x}_{i t}\right)$. Thus the $(5 \mathrm{~b})$ function is expressed by:

$$
\begin{aligned}
u_{i t}= & \delta_{0}+\delta_{1} \text { Age }_{i t}+\delta_{2} \text { InIntermediate input }_{i t}+\delta_{3} \operatorname{lnLabour}_{i t}+\delta_{4} \ln \text { Capital }_{i t}+ \\
& \delta_{t} \text { Time }_{i t}+W_{i t}
\end{aligned}
$$

The variable Age was selected in order to evaluate the role of experience in technical efficiency. We assume that older firms are more efficient than newer ones because they have accumulated experience and knowledge (learning by doing) that allow them to improve their technical and economic performance (Nelson and Winter, 1982).

\section{Results and Discussion}

\section{The Frontier Model}

The parameters for the function and inefficiency model were estimated simultaneously, using the computer programme FRONTIER 4.1, created by Coelli (1996). The results of the ML estimates on the Translog function model (5) are reported in Table 1. The original model was, however, repeatedly tested, in order to evaluate whether the adopted model was statistically significant and suitable for the data used.

We used the Generalised likelihood-ratio test as a testing procedure. This allowed us to compare a restricted model with the adopted model (Bohrnstedt and Knoke, 1994). The statistic associated with this test is defined as:

$$
l=-2 \ln L=-2\left[\ln \frac{L(H 0)}{L(H 1)}\right]=-2\left[\ln L\left(H_{0}\right)-\ln L\left(H_{1}\right)\right]
$$

where $\mathrm{L}\left(H_{1}\right)$ and $\mathrm{L}\left(H_{0}\right)$ are the log-likelihood value of the adopted model and of the restricted model respectively. The statistic test parameter $\lambda$ has, approximately, a chisquare (or a mixed-square) distribution with a number of degrees of freedom equal to the number of parameters (restrictions). These are assumed to be zero in the nullhypothesis $\mathrm{H}_{0}{ }^{[\mathrm{f}]}$.

A first set of tests was applied to the frontier model. We tested the null-hypotheses of adopting a Hicks-neutral technical change function $\left(H_{0}: \beta_{1 \mathrm{t}} ; \beta_{2 \mathrm{t}} ; \beta_{3 \mathrm{t}}=0\right)$, of adopting a non-technological change in the observed panel $\left(H_{0}: \beta_{\mathrm{t}}, \beta_{1 \mathrm{t}}, \beta_{2 \mathrm{t}}, \beta_{3 \mathrm{t}}, \beta_{\mathrm{tt}}=0\right)$, and of adopting a Cobb-Douglas specification form to describe the frontier production $\left(H_{0}: \beta_{i j}=0\right)$, respectively.

We also tested if there were technological differences between private firms and cooperatives. If the null hypothesis $H_{0}: \beta_{\mathrm{p}}=0$ is rejected, this means that cooperatives and private firms use different technologies and lie on different frontier functions.

The results in Table 2 suggest that the former two hypotheses can be rejected, but that the hypothesis of the functional form of the frontier cannot be rejected. This implies that the Cobb-Douglas frontier is a more adequate representation of the data than the Translog frontier. 
Table 1 ML estimates for SFA parameters and for TE

\begin{tabular}{|c|c|c|c|}
\hline Variable & Parameter & Translog ${ }^{(1)}$ & Cobb-Douglas ${ }^{(2)}$ \\
\hline \multicolumn{4}{|l|}{ FRONTIER MODEL } \\
\hline Constant & $\beta_{0}$ & $2.888(0.121)$ & $1.161(0.168)$ \\
\hline Intermediate inputs & $\beta_{1}$ & $0.101(0.148)$ & $0.662(0.036)$ \\
\hline Labour & $\beta_{2}$ & $0.557(0.162)$ & $0.249(0.037)$ \\
\hline Capital & $\beta_{3}$ & $0.012(0.044)$ & $0.098(0.023)$ \\
\hline Private/ coop. & $\beta_{p}$ & $-0.013(0.063)$ & - \\
\hline Year & $\beta_{t}$ & $-0.114(0.074)$ & $0.011(0.008)$ \\
\hline (Inter. Inputs × Inter. inputs) & $\beta_{11}$ & $0.098(0.022)$ & - \\
\hline (Intermediate inputs $\times$ Labour) & $\beta_{12}$ & $-0.278(0.160)$ & - \\
\hline (Intermediate inputs $\times$ Capital) & $\beta_{13}$ & $0.049(0.034)$ & - \\
\hline (Intermediate inputs $\times$ Year) & $\beta_{1 \mathrm{t}}$ & $0.089(0.035)$ & - \\
\hline (Labour × Labour) & $\beta_{22}$ & $0.124(0.058)$ & - \\
\hline (Labour × Capital) & $\beta_{23}$ & $0.010(0.015)$ & - \\
\hline (Labour $\times$ Year) & $\beta_{2 t}$ & $-0.018(0.015)$ & - \\
\hline (Capital × Capital) & $\beta_{33}$ & $-0.013(0.011)$ & - \\
\hline (Capital × Year) & $\beta_{3 t}$ & $0.013(0.009)$ & - \\
\hline (Year $\times$ Year) & $\beta_{\mathrm{tt}}$ & $0.008(0.003)$ & - \\
\hline \multicolumn{4}{|l|}{ EFFICIENCY EFFECTS } \\
\hline Constant & $\delta_{0}$ & $0.781(0.328)$ & - \\
\hline Age & $\delta_{1}$ & $-0.344(0.185)$ & $-0.188(0.121)$ \\
\hline Intermediate inputs & $\delta_{2}$ & $-0.299(0.183)$ & $-0.172(0.152)$ \\
\hline Labour & $\delta_{3}$ & $-0.415(0.251)$ & $-0.363(0.237)$ \\
\hline Capital & $\delta_{4}$ & $0.668(0.454)$ & $0.614(0.365)$ \\
\hline Year & $\delta_{t}$ & $-0.026(0.019)$ & $-0.028(0.020)$ \\
\hline \multicolumn{4}{|l|}{ VARIANCE PARAMETERS } \\
\hline$\sigma^{2}=\sigma_{u}^{2}+\sigma_{v}^{2}$ & $\sigma^{2}$ & $0.081(0.054)$ & $0.062(0.041)$ \\
\hline$\gamma=\sigma_{u}^{2} /\left(\sigma_{u}^{2}+\sigma_{v}^{2}\right)$ & Y & $0.885(0.085)$ & $0.864(0.104)$ \\
\hline$\gamma *=\gamma /\left[\gamma+\frac{1-\gamma}{\pi /(\pi-2)}\right]$ & $\gamma^{*}$ & 0.954 & 0.946 \\
\hline Log-likelihood function & & 32.305 & 23.560 \\
\hline Mean TE & & $\mathbf{0 . 8 9 8}(0.090)$ & $0.905(0.091)$ \\
\hline Returns to scale & & 1.022 & 1.009 \\
\hline
\end{tabular}

${ }^{(1)}$ Adopted Model (Translog) ${ }^{(2)}$ Preferred Model (Cobb-Douglas with no $\delta_{0}$ intercept).

$Y^{*}$ is described in the text below.

The null hypothesis on technological homogeneity between the two organisational forms is also not rejected, so private firms and cooperatives lie on the same frontier function.

A second set of tests associated with the inefficiency model was conducted using the Cobb-Douglas function model ${ }^{[f]}$. These tests were designed to verify the following: whether the neutral model is more suitable for the data than the non-neutral one $\left(H_{0}\right.$ : $\left.\delta_{2} ; \delta_{3} ; \delta_{4}=0\right)$; whether the inefficiency effects are absent from the model $\left(H_{0}: \gamma=\delta_{0}\right.$; $\left.\delta_{1} ; \ldots \delta_{\mathrm{n}}=0\right)$; whether the nature of the inefficiency effects are stochastic or not $\left(H_{0}\right.$ : $\left.\gamma=\delta_{0} ; \delta_{2} ; \delta_{3} ; \delta_{4}=0\right)$ : whether the inefficiency effects have an intercept $\left(H_{0}: \delta_{0}=0\right)$; whether no firm-specific factors exist $\left(H_{0}: \delta_{1} ; \ldots \delta_{\mathrm{n}}=0\right)$; and whether Age is a significant explanatory variable of the model $\left(H_{0}: \delta_{1}=0\right)^{[\mathrm{h}]}$. 
Table 2 Hypothesis testing for the adopted model

\begin{tabular}{|c|c|c|c|c|c|c|}
\hline Restrictions & Model & $\mathrm{L}\left(H_{0}\right)$ & $\lambda$ & d.f. & $\chi_{0.95}^{2}$ & Decision \\
\hline None & $\underline{\text { Translog, non neutral }}$ & 32.31 & & & & \\
\hline$H_{0}: \beta_{1 \mathrm{t}} ; \beta_{2 \mathrm{t} ;} \beta_{3 \mathrm{t}}=0$ & Hicks-neutral technical change & 24.77 & 15.06 & 3 & 7.82 & Rejected \\
\hline$H_{0}: \beta_{\mathrm{t},} \beta_{1 \mathrm{t}}, \beta_{2 \mathrm{t}}, \beta_{3 \mathrm{t},}, \beta_{\mathrm{tt}}=0$ & No technical change & 20.86 & 22.89 & 5 & 11.67 & Rejected \\
\hline$H_{0}: \beta_{p}=0$ & Technological homogeneity & 30.85 & 2.90 & 1 & 3.84 & $\underline{\text { Not reject }}$ \\
\hline$H_{0}: \beta_{i j}=0$ & Cobb-Douglas & 23.71 & 17.19 & 10 & 18.31 & Not reject \\
\hline None & Cobb Douglas & 23.71 & & & & \\
\hline$H_{0}: \delta_{2} ; \delta_{3} ; \delta_{4}=0$ & Neutral & 17.73 & 11.96 & 3 & 7.82 & Rejected \\
\hline$H_{0}: \gamma=\delta_{1} \ldots \delta_{n}=0$ & No inefficiency effects & 20.82 & 5.77 & 6 & $11.91^{*}$ & Rejected \\
\hline$H_{0}: \gamma=\delta_{0} ; \delta_{2} ; \delta_{3} ; \delta_{4}=0$ & No stochastic effects & 21.06 & 5.30 & 5 & $10.37^{*}$ & Rejected \\
\hline$H_{0}: \delta_{0}=0$ & No intercept & 23.09 & 1.24 & 1 & 3.84 & $\underline{\text { Not reject }}$ \\
\hline$H_{0}: \delta_{1} ; \ldots \delta_{n}=0$ & No firm-specific factors & 16.86 & 13.68 & 4 & 9.49 & Rejected \\
\hline$H_{0}: \delta_{1}=0$ & No Age effects & 21.59 & 4.04 & 1 & 3.84 & Rejected \\
\hline
\end{tabular}

* Critical values with an asterisk are taken from Kodde and Palm (1986). For these variables the statistic $\lambda$ follows a mixed $\chi^{2}$ distribution.

Our results suggest that all the above hypotheses can be rejected, with the exception of the hypothesis on the absence of the intercept in the inefficiency model. The preferred model is thus a Cobb-Douglas frontier function in which the parameter $\delta_{0}$ is equal to zero (see last column of Table 1).

\section{Structure of production and technical efficiency}

The estimated function satisfies both properties of monotonicity (all parameters are positive) and diminishing marginal productivity (the magnitude is lower than unity for each parameter) (Table 1).

The estimated production elasticities suggest that intermediate inputs are by large the most important input in conditioning productivity. The production elasticity associated with this variable is 0.662 and this suggests that a $1 \%$ increase (or reduction) in intermediate inputs would produce, all other things being equal, a corresponding increase (or reduction) in production of $0.66 \%$. The estimated elasticities of the other two inputs are lower ( 0.249 for labour and 0.098 for capital). Returns to scale are estimated to be substantially constant (1.009)

The time variable is positive, but the low magnitude $(0.011)$ means that time does not greatly affect production.

Analysis of the technical efficiency of sheep dairy firms shows that, on average, they use their technology with $90.5 \%$ efficiency. Since it is an output-oriented measure, this result suggests that, if technology remains at the present levels and sheep dairy firms use their disposable resources more effectively, they would only be able to increase output by about $10 \%$.

Estimation of the ratio-parameter $\gamma$ gives information on the weight of technical efficiency on production. The estimated $\gamma$ is significant (for $\alpha=0.01$ ) and this implies that differences in technical efficiency among firms are relevant for explaining variations in output in the sample (more than $80 \%$ of the variability on the whole). However, this parameter value could not be taken as a measure of the relative contribution of the inefficiency term to total output variance, because this measure can be obtained by estimating the ratio-parameter $\gamma^{*}$. 
Parameter $\gamma^{*}$ is also significant (for $\alpha=0.01$ ), which indicates that about $95 \%$ of the general differential between observed and best-practice output is due to the existing difference in efficiency among firms $\left(\gamma^{*}=0.946\right)$, i.e., it suggests that technical efficiency might play a crucial role among the factors affecting productivity in the sheep dairy firms.

Finally, on the basis of the specific estimated scores reported by each firm, there was on average a significant difference (for $\alpha=0.01$ ) in technical efficiency between private firms $(\mathrm{TE}=0.933)$ and cooperatives $(\mathrm{TE}=0.877)($ Table 3$)$.

\section{Source of inefficiency}

Our estimated findings suggest that, as expected, the age of the firms $(-0.188)$ is positively (negatively) related to technical efficiency (inefficiency). They suggest that older firms tend to be more efficient, even if only slightly, than newer firms. This is probably because they have accumulated the experience and knowledge (learning by doing) that permits them to improve their technical performance over time. In addition, ML estimates of the relationship between technical efficiency and inputs show that all inputs play a significant role in determining efficiency. Using intermediate inputs $(-0.172)$ and labour (-0.028) affects efficiency positively, while we found that a firm's inefficiency was strongly related to the capital endowment (0.614). In other words, technical efficiency tends to decrease when capital increases in sheep dairy firms.

In conclusion, the empirical findings suggest that sheep dairy firms tend to become more efficient over time, although the magnitude of the increase is extremely low (0.028), which indicates that the time factor has only a weak effect on efficiency levels.

\section{Conclusions}

The model's results allow us to present some arguments which need to be explored in more depth in further studies.

i. Technological homogeneity. $95 \%$ of the variance of performances is explained by differences in technical efficiency. In other words, results suggest that any significant differences exist in processing technologies in the sample. This technological homogeneity applies to all types of Sardinian firms and can be partly explained by the overwhelming dominance of PR cheese in the sheep dairy industry, where other products have to share the same factories with PR. In our opinion this is only part of the story, because the same performance levels were found in the few firms where PR was not produced or made up only a small part of the production. This technological homogeneity was found in both private firms and cooperatives, and sheds light on the well-defined strategic choices made by the

Table 3 Estimated technical efficiency in private firms and cooperatives

\begin{tabular}{lrrr}
\hline TE & Private & Cooperatives & TOTAL \\
\hline Mean & 0.933 & 0.877 & 0.905 \\
S.d. & $(0.057)$ & $(0.110)$ & $(0.091)$ \\
Max & 1.000 & 0.980 & 1.000 \\
Min & 0.717 & 0.544 & 0.544 \\
No. of firms & 18 & 18 & 36 \\
No. of observations (6 years) & 108 & 108 & 216 \\
\hline
\end{tabular}


Sardinian sheep industry as a whole when the question of adopting new technology arises. Constant returns to scale strengthen the idea of widespread homogeneity in technological levels in the region among both large and small firms, almost as though there was a modular processing technique.

ii. Limited scope for recovering efficiency. We cannot place great reliance on recovering efficiency. Despite the relative and not absolute meaning of the term "efficiency" used here, we have to recognize that the mean TE of the Sardinian sheep dairy industry is $90 \%$, with private firms having a TE of $93 \%$ and cooperatives a TE of $87 \%$. This means that full exploitation of the factors of production would allow each firm to increase its output by a mean value of 606,000 Euros. If one bears in mind that our survey covered 36 of the 50 Sardinian firms, then it is reasonable to assume that the total loss to the industry is 30 million Euros. Thus, this can be considered to have a significant but not decisive impact on the agri-food integrated system.

iii. The role of raw material, capital and other inputs. The raw material (milk) to be processed and labour inputs showed high production elasticities and TE. Capital input is, however, associated with a low production elasticity, and has a decreasing effect on TE. This is an unequivocal sign of excessive investment and under-exploitation of the plants' production capacities. As is well known, the firms stop processing activities in the summer due to the lack of milk, and the plants only work for a limited number of hours during the day. Recovering efficiency, where it is worth it, means increasing the volume of milk to be processed and more intensive employment of workers. There is a conflict between arguing for improving efficiency and the present market conditions, where producers are facing difficulties in selling accumulated surpluses of PR. The technical solution to the problem is therefore to change the conditions of the market. Another important factor in recovering efficiency is experience. We found a significant relationship between TE elasticity and the age of the firm. Experience is a strategic tool that can be used to develop the Sardinian sheep dairy industry.

Summing up the above arguments, we can state that the processing part of the Sardinian sheep milk agribusiness carries out its role effectively. In other words, farmers cannot blame industrial entrepreneurs for the differences in prices of the finished products and the prices paid to primary producers for the raw materials. On the other hand, there is some limited space for improving milk processing performances, and these can be exploited at present. Undoubtedly, oversized capital investment, rather than underemployment of raw materials and labour, seems to be the most important limiting factor in the performance of the industry.

Efficient use of processing plants needs to be supported in two ways: first, the raw material needs to be supplied for a longer period; second, the plants need to be used for longer periods of the day. The former objective encounters some problems related to the close link between the availability of natural forage resources and the reproductive activity of the animals. Refrigerating the milk could help to overcome this problem, as well as also having the additional advantage of making milk available for producing fresh dairy products, such as cottage cheese, which are in high demand during the summer. However, it must be recognised that this solution is in contradiction with the problem of the under-exploitation of the plants in the other seasons. This leads us to suggest an alternative solution. Given the accumulation of unsold PR surpluses, suggesting that the 
more plants should be used more intensively by increasing the volume of milk to be processed seems inappropriate. It is more realistic to envisage a solution where the number of processing plants and their production capacity is appropriate for the market demand for the final product. In other words, analysis of technical efficiency cannot be treated separately from marketing strategies.

The three issues addressed here - technical homogeneity, recovery of efficiency and overcapitalization - seem to suggest that decision makers should converge on the same strategic option, i.e. diversification. This does not necessarily or exclusively mean broadening the Sardinian dairy industry supply basket. It also has to be seen as a strong recommendation for re-organising the entire processing and marketing system by breaking the circle of technological homogeneity and finding new outlets for new as well as existing final products.

\section{Endnotes}

${ }^{a}$ After Wales, Scotland and Castile and Leon (Spain), Sardinia has the largest number of dairy sheep in the EU.

b When firm operates in a constant return to scale area the input and outputoriented measures coincide (Fare and Lovell, 1978).

${ }^{c}$ Following the suggestion made by Battese and Corra (1977), Battese and Coelli (1995) suggest replacing the parameter $\lambda=\sigma_{u} / \sigma_{v}$ originally proposed in the SFA models with $\gamma$ because it can be searched for between zero and one. This allows us to obtain a suitable starting value for an iterative maximisation process.

${ }^{d}$ Ethical concerns: no experimental research on humans or animals have been carried out.

e The authors wish to thank the C.C.I.A.A. of Sassari for allowing us to collect the data. For more information about the Register of the Companies and data, see http:// www.registroimprese.it.

${ }^{\mathrm{f}}$ When $\lambda$ is lower than the correspondent critical value (for a given significance level), we cannot reject the null-hypothesis.

g Tests on Translog specification produced similar results to these applied on the Cobb-Douglas specification. In Table 2 only the test estimations on the preferred specification of the frontier (Cobb-Douglas) are reported.

${ }^{\mathrm{h}}$ If the null hypothesis $H_{0}: \delta_{m}=0$ is not rejected, the model can be substantially described by the neutral function model explained by (3) and originally proposed by Battese and Coelli (1995).

\section{Competing interests}

The authors declare that they have no competing interests.

\section{Authors' contributions}

The study was jointly carried out by the authors. However, RF wrote the paragraph 1, FA Madau wrote the paragraph 2 and 3, and PP wrote the paragraph 4. All authors read and approve the final manuscript.

Received: 14 May 2012 Accepted: 8 March 2013

Published: 15 May 2013

References

Aigner DJ, Lovell CAK, Schmidt PJ (1977) Formulation and Estimation of Stochastic Frontier Production Function Models, J. Econom 6(1):21-37

Atkinson SE, Cornwell C (1994) Estimation of Output and Input Technical Efficiency Using a Flexible Functional Form and Panel Data. Int Econ Rev 35(1):245-255 
Battese GE, Coelli TJ (1995) A Model for Technical Inefficiency Effects in a Stochastic Frontier Production Function for Panel Data, Empir. Econ 20(2):325-332

Battese GE, Corra GS (1977) Estimation of a Production Frontier Model: With Application to the Pastoral Zone of Eastern Australia. Austr J Agr Econ 21(3):169-179

Bohrnstedt GW, Knoke D (1994) Statistics for Social Data Analysis. F.E. Peacock Publishers Inc., Itasca

Coelli TJ (1996) A Guide to Frontier Version 4.1: A Computer Program for Stochastic Frontier Production and Cost Function Estimation. CEPA Working Papers 7/96. Department of Econometrics, University of New England, Armidale, of New England, Armidale

Consorzio per la tutela del formaggio Pecorino Romano (2011) Dati sulla produzione., http://www.pecorinoromano. com. Accessed February 8, 2011

Eurostat (2011) Database Statistics., http://epp.eurostat.ec.europa.eu/portal/page/portal/agriculture/data/database, Accessed February 8, 2011

FAO (2011) FAOSTAT, Production, Livestock Primary., http://faostat.fao.org/site/569/default.aspx\#ancor. Accessed February 7, 2011

Färe R, Lovell CAK (1978) Measuring the Technical Efficiency of Production. J Econ Theory 19:150-162

Farrell MJ (1957) The Measurement of Productive Efficiency. J R Stat Soc 3:253-290

FAS-USDA (2011) FAS-USDA (2010) U.S., http://www.fas.usda.gov/ustrade, Accessed February 8, 2011

Greene WH (1980) On the Estimation of a Flexible Frontier Production Model, J. Econ 13(1):101-115

Huang CJ, Liu JT (1994) Estimation of a Non-Neutral Stochastic Frontier Production Function. J Prod Anal 5(1):171-180

Idda L, Furesi R, Pulina P (2010a) L'allevamento ovino in Sardegna tra crisi di mercato e politiche per il rilancio. Agriregionieuropa 23:65-68

Idda L, Furesi R, Pulina P (2010b) Economia dell'allevamento ovino da latte - Produzione, trasformazione, mercato. Franco Angeli, Milan

Istat (2011) Sistema Informativo su Agricoltura e Zootecnia., http://agri.istat.it/jsp/dawinci.jsp?q=plB040000030000103200\&an= 2009\&ig=1\&ct=204\&id=8A|9A, Accessed February 8, 2011

Jondrow J, Lovell CAK, Materov IS, Schmidt P (1982) On the Estimation of Technical Inefficiency in the Stochastic Frontier Production Functions Model, J. Econometrics 19:233-238

Karagiannis G, Tzouvelekas V (2005) Explaining Output Growth with a Heteroscedastic Non-neutral Production Frontier: the Case of Sheep Farms in Greece. Eur Rev Agric Econ 32(1):51-74

Kodde DA, Palm FC (1986) Wald Criteria for Jointly Testing Equality and Inequality. Econometrica 54(5):1243-1248

Kumbhakar SC, Lovell CAK (2000) Stochastic Frontier Analysis. Cambridge University Press, New York

Kumbhakar SC, Ghosh S, McGuckin T (1991) A Generalized Production Frontier Approach for Estimating Determinants of Inefficiency in U.S. Diary Farms. J Bus Econ Stat 9:279-286

Meeusen W, van den Broeck J (1977) Efficiency Estimation from Cobb-Douglas Production Function with Composed Error. Int Econ Rev 18(2):435-444

Nelson RR, Winter SG (1982) The Schumpterian Tradeoff Revisited. Amer Econ Rev 72(1):114-132

Reifschneider D, Stevenson R (1991) Systematic Departures from the Frontier: A Framework for the Analysis of Firm Inefficiency. Int Econ Rev 32(3):715-723

doi:10.1186/2193-7532-1-4

Cite this article as: Furesi et al:: Technical efficiency in the sheep dairy industry: an application on the Sardinian (Italy) sector. Agricultural and Food Economics 2013 1:4

\section{Submit your manuscript to a SpringerOpen ${ }^{\circ}$ journal and benefit from:}

- Convenient online submission

- Rigorous peer review

- Immediate publication on acceptance

- Open access: articles freely available online

- High visibility within the field

- Retaining the copyright to your article

Submit your next manuscript at $\gg$ springeropen.com 